\title{
Influence of anions and solvent molecules on the packing and emission spectra of coordination polymers based on silver ions and an anthracene derivative $\dagger$
}

\author{
Jing Chen, ${ }^{\text {ad }}$ Noémie Voutier, ${ }^{a}$ Jamshid Rajabi, (1Da Aurélien Crochet, (1D ${ }^{b}$ \\ Dario M. Bassani (iD ${ }^{c}$ and Katharina M. Fromm (D) *a
}

\begin{abstract}
Luminescence between green and blue was observed in the solid state for the free ligand $\mathrm{L}$ (anthracene9,10-diylbis(methylene) dinicotinate) and five different $\mathrm{Ag}-\mathrm{L}$ coordination polymers upon excitation at 344 $\mathrm{nm}$. Depending on the packing of the anthracene moieties due to coordinating anions and the presence or absence of solvent molecules, the emission maximum is shifted.
\end{abstract}

Anthracene derivatives are designed and synthesized as typical luminescent materials ${ }^{1}$ both in solution and in the solid state, such as in phosphors and lasers. ${ }^{2}$ 9- Or 9,10substituted anthracene derivatives are constructed to be used as chemosensors to detect alkali, alkaline-earth, and transition metal cations, and even some anions, for example halides, acetate and dihydrogenphosphate. ${ }^{3}$ Anthracene has the ability to undergo photodimerization under irradiation by UVlight and to yield excimer emission for luminescence. Excimer formation is a phenomenon that is rarely observed in metal organic frameworks (MOFs). Typically, excimer and exciplex formation in MOFs could be achieved by infiltration with an appropriate guest molecule to form a featureless emission spectrum. ${ }^{4}$ Indeed, Zaworotko and co-workers synthesized several porous coordination polymers showing exciplex formation by guest molecule intercalation, assuming a cofacial arrangement between 4,4'-bipyridine of the MOF and pyrene as the guest molecule. ${ }^{5}$ However, excimer formation due to overlapping identical moieties is uncommon because it does not generally lead to strong electronic interactions. ${ }^{6}$ We have previously shown examples with an isonicotinic acid derived 9,10-substituted anthracene ligand. ${ }^{7}$ Herein, we introduce the

${ }^{a}$ Department of Chemistry, University of Fribourg, Chemin du Musée 9, CH-1700 Fribourg, Switzerland. E-mail: Katharina.Fromm@unifr.ch; Fax: +41 263009738; Tel: +41263008732

${ }^{b}$ Fribourg Center for Nanomaterials, University of Fribourg, Chemin du Musée 9, CH-1700 Fribourg, Switzerland

${ }^{c}$ Institut des Sciences Moléculaires CNRS UMR5255, Univ. Bordeaux, 351, Cours de la Libération, 33400 Talence, France

${ }^{d}$ Xiamen Institute of Rare-earth Materials, Haixi Institutes, Academy of Sciences, Xiamen, Fujian, 361021, China

$\dagger$ Electronic supplementary information (ESI) available: Labelled ORTEP figures of repeat units of all compounds, interactions in $\mathbf{5}$ and overlays of ligands. CCDC 1413537-1413540 (L, 3, 2, 5), 1547594 (1), 1547595 (4). For ESI and crystallographic data in CIF or other electronic format see DOI:10.1039/c7ce00846e nicotinic acid 9,10-functionalized anthracene ligand $\mathbf{L}$ (anthracene-9,10-diylbis(methylene)dinicotinate) (Fig. 1), which was initially designed by our group as a luminescent donor ligand for the formation of antimicrobial coordination polymers based on silver, in order to be able to monitor bacterial metabolism upon ingestion of our polymers by bacteria. ${ }^{8}$

Since we had shown before that silver coordination polymers based on the isonicotinic acid derivative ${ }^{7}$ possessed excimer emission in the range between green and blue, we decided to investigate the role of counter ions and solvent molecules in

a)

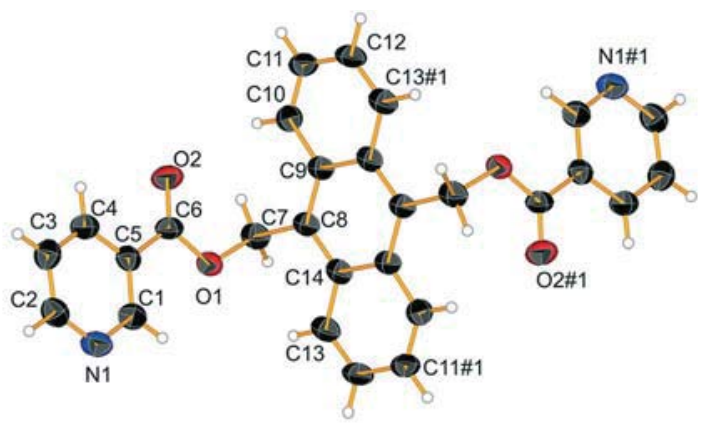

b)

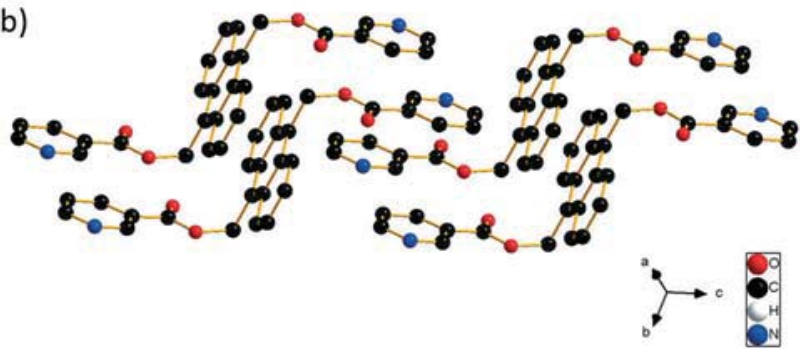

Fig. 1 L, anthracene-9,10-diylbis(methylene)dinicotinate. a) Molecular view. b) Packing in the crystal structure $(\mathrm{H}$-atoms are omitted for clarity). 
the final structure and consequently the photoluminescence properties of the nicotinic acid derived compounds.

\section{Experimental section}

Preparation of ligand $L$

To a stirred suspension of 9,10-bischloromethylanthracene $\mathrm{e}^{16}$ $(1.47 \mathrm{~g}, 5.36 \mathrm{mmol})$ and nicotinic acid $(1.32 \mathrm{~g}, 10.72 \mathrm{mmol})$ in $10 \mathrm{ml}$ dry DMF under $\mathrm{N}_{2}, \mathrm{Cs}_{2} \mathrm{CO}_{3}(3.5 \mathrm{~g}, 10.742 \mathrm{mmol})$ was added. The mixture was reacted for $24 \mathrm{~h}$ at room temperature. The solvent was removed and the residue was washed with water, filtered and washed with acetone. After drying in air, the crude product was collected and purified by column chromatography $\left(\mathrm{CH}_{2} \mathrm{Cl}_{2} / \mathrm{Et}_{2} \mathrm{O}=1: 1\right)$ to give ligand $\mathrm{L}$. The yield of the crude product was about $89 \%$, and after purifying by column chromatography, the yield of the pure product was around 40\%. (Mp: $\left.228{ }^{\circ} \mathrm{C}\right), \mathrm{MS}(\mathrm{EI}): m / z\left(\mathrm{M}^{+}\right) .449 .2 .{ }^{1} \mathrm{H} \mathrm{NMR}(360 \mathrm{MHz}$, $\left.\mathrm{CDCl}_{3}\right): \delta 9.19(\mathrm{~s}, 2 \mathrm{H}), 8.73(\mathrm{~d}, J=4.0,2 \mathrm{H}), 8.54(\mathrm{dd}, J=6.9,3.0$, $2 \mathrm{H}), 8.24(\mathrm{~d}, J=8.0,4 \mathrm{H}), 7.66(\mathrm{dd}, J=6.9,3.0,2 \mathrm{H}), 7.31(\mathrm{dd}, J=$ 7.5, 5.1, $4 \mathrm{H}), 6.484(\mathrm{~s}, 4 \mathrm{H})$. Anal cal for $\mathrm{C}_{28} \mathrm{H}_{20} \mathrm{~N}_{2} \mathrm{O}_{4}$ : C, 74.98\%; $\mathrm{H}, 4.50 \%$; N, 6.25\%; found: C, 75.68\%; H, 4.61\%; N, 6.29\%. IR $\left(\mathrm{KBr}, \mathrm{cm}^{-1}\right): 1724$ s, $1589 \mathrm{~s}, 1477 \mathrm{w}, 1447 \mathrm{w}, 1426 \mathrm{~m}, 1386 \mathrm{w}$, 1352 m, 1272 s, 1196 m, 1096 s, 1023 s, 978 w, 954 w, 925 m, 812 m, $782 \mathrm{~m}, 753 \mathrm{~s}, 740 \mathrm{~s}, 701 \mathrm{~m}, 667 \mathrm{~m}, 620 \mathrm{w}, 577 \mathrm{w}, 433 \mathrm{w} \mathrm{cm}^{-1}$.

\section{Synthesis of complex $1\left[\mathrm{Ag}-\mathrm{L}\left(\mu-\mathrm{CF}_{3} \mathrm{SO}_{3}\right)\right]_{n}$}

A solution of $0.1 \mathrm{mmol}$ of $\mathbf{L}$ in $20 \mathrm{~mL}$ DCM was placed in a vial. A $20 \mathrm{~mL}$ mixture of DCM and $\mathrm{CH}_{3} \mathrm{OH}(1: 1)$ was slowly layered on top of the solution. Finally, a solution of silver

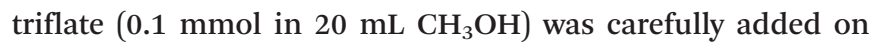
top of the mixture. After one week, translucent yellow needles suitable for single crystal X-ray diffraction were obtained, which turned plain yellow when filtered and dried. The PXRD of the plain yellow crystals matched the theoretical PXRD calculated from the single crystal X-ray diffraction data. Yield (1): $70 \%$. Elemental analysis: calculated: C, $49.38 \mathrm{H}, 2.86 \mathrm{~N}$, $3.97 \mathrm{~S}, 4.55 \%$; found: C, $48.50 \mathrm{H}, 2.72 \mathrm{~N}, 3.80 \mathrm{~S}, 4.51 \%$. IR $\left(\right.$ ATR, cm ${ }^{-1}$ ): 3065 w, 1715 m, 1599 w, 1450 w, 1431 w, 1390 w, 1358 w, 1334 w, 1280 b, 1231 m, 1214 m, 1200 m, 1175 m, $1155 \mathrm{~m}, 1110 \mathrm{~m}, 1046 \mathrm{~m}, 1019 \mathrm{~m}, 903 \mathrm{~m}, 812 \mathrm{~m}, 787 \mathrm{~m}, 743$ sh, $693 \mathrm{~m}, 665 \mathrm{~m}, 631 \mathrm{~m}, 570 \mathrm{~m}, 515 \mathrm{sh}, 426 \mathrm{~m} \mathrm{~cm}^{-1}$.

\section{Syntheses of complexes 2 and 3}

Syntheses of complexes 2 and 3 are accomplished by the same method. A typical process is as follows: slow diffusion

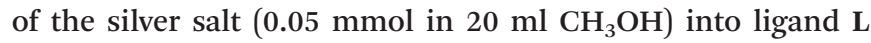
( $0.05 \mathrm{mmol}$ in $20 \mathrm{ml}$ dichloromethane) through a mixed solvent of $\mathrm{CH}_{3} \mathrm{OH}$ : DCM $(1: 1)$. Several weeks later, crystals suitable for single crystal X-ray diffraction were obtained. Yield (2) $\left\{[\mathrm{Ag} \cdot \mathrm{L}]\left(\mathrm{CF}_{3} \mathrm{SO}_{3}\right) \cdot \mathrm{CH}_{3} \mathrm{OH}\right\}_{n}: 18 \mathrm{mg}(50 \%$ calculated with respect to $\mathrm{Ag}$ ). Elemental analysis: calculated: $\mathrm{C}, 48.86 \mathrm{H}, 3.28$ $\mathrm{N}, 3.80 \%$; found: C, $49.82 \mathrm{H}, 2.83 \mathrm{~N}, 3.82 \%$ (the experimental values correspond well to compound 2 after loss of methanol: $\mathrm{C}, 49.38 \mathrm{H}, 2.86 \mathrm{~N}, 3.97 \%)$. IR (KBr, $\left.\mathrm{cm}^{-1}\right): 1721 \mathrm{~s}, 1626 \mathrm{w}$, 1599 m, 1530 w, 1481 w, 1451 w, 1433 m, 1390 w, 1359 m, 1282 s, 1233 s, 1216 m, 1201 w, 1176 w, 1158 m, 1112 s, 1047 w, 1021 s, 951 w, 904 m, 834 w, 813 w, 788 m, 744 s, 694 m, 665 w, $633 \mathrm{~s}, 599 \mathrm{w} \mathrm{cm}^{-1}$. Yield (3) $\left\{[\mathrm{Ag} \cdot \mathrm{L}]\left(\mathrm{NO}_{3}\right) \cdot \mathrm{CH}_{3} \mathrm{OH}\right\}_{n}: 16 \mathrm{mg}(55 \%$ calculated with respect to $\mathrm{Ag}$ ). Elemental analysis: calculated: C, $53.56 \mathrm{H}, 3.72 \mathrm{~N}, 6.46 \%$; found: C, $53.36 \mathrm{H}, 3.67, \mathrm{~N}, 6.22 \%$. IR $\left(\mathrm{KBr}, \mathrm{cm}^{-1}\right)$ : 1729 s, 1603 m, 1530 w, 1475 w, 1437 w, 1354 w, 1320 w, 1274 s, 1199 w, 1183 w, 1114 s, 1044 m, 929 m, 884 w, 822 w, 784 w, 740 s, 694 m, 650 w, 601 w, $586 \mathrm{w} \mathrm{cm}^{-1}$.

\section{Synthesis of complex $4\left\{\left[\mathrm{AgL}\left(\mu-\mathrm{NO}_{3}\right)\right] \mathrm{EtOH}\right\}_{n}$}

A solution of $0.1 \mathrm{mmol}$ of $\mathbf{L}$ in $20 \mathrm{~mL}$ DCM was placed in a vial. A $20 \mathrm{~mL}$ mixture of DCM and $\mathrm{CH}_{3} \mathrm{CH}_{2} \mathrm{OH}(1: 1)$ was slowly layered on top of the solution. Finally, a solution of silver nitrate $\left(0.1 \mathrm{mmol}\right.$ in $\left.20 \mathrm{~mL} \mathrm{CH}_{3} \mathrm{CH}_{2} \mathrm{OH}\right)$ was carefully added on top of the mixture. After one week, yellow crystals were obtained. Yield (4): $60 \%$. Elemental analysis: calculated: C, $54.23 \mathrm{H}, 3.94 \mathrm{~N}, 6.32 \%$; found: C, $54.37 \mathrm{H}, 2.56 \mathrm{~N}, 6.66 \%$. IR (ATR, cm ${ }^{-1}$ ): 3425 b, 3374 b, 3103 w, 3075 w, 3039 w, 1721 m, $1600 \mathrm{w}, 1584 \mathrm{w}, 1472 \mathrm{w}, 1434 \mathrm{~m}, 1331 \mathrm{~m}, 1278 \mathrm{~s}, 1203 \mathrm{sh}$, 1186 sh, 1111 s, 1051 sh, 1029 sh, 953 w, 919 m, 842 w, 816 m, $787 \mathrm{~m}, 744 \mathrm{~s}, 692 \mathrm{sh}, 493 \mathrm{~m} \mathrm{~cm}^{-1}$.

\section{Synthesis of complex $5\left[\mathrm{Ag}\left(\mathrm{NO}_{3}\right) \mathrm{L}_{2}\right]_{n}$}

Silver nitrate $\left(0.1 \mathrm{mmol}\right.$ in $\left.20 \mathrm{ml} \mathrm{CH} \mathrm{CH}_{3} \mathrm{OH}\right)$ was added into the ligand solution $(0.1 \mathrm{mmol}$ in $20 \mathrm{ml}$ dichloromethane), and a yellow precipitate formed immediately, which was filtered and washed with methanol and dichloromethane, then dried in air. The yellow powder was dissolved in DMF and the same quantity of ethanol was added into the solution to prepare a $0.1 \mathrm{mmol} \mathrm{L}^{-1} \mathrm{DMF} / \mathrm{EtOH}$ solution. After several weeks, yellow crystals suitable for single crystal X-ray diffraction were obtained. Yield (5): $4 \mathrm{mg}$ (13\% calculated with respect to $\mathrm{Ag}$ ). Elemental analysis: calculated: C 54.39, H 3.26, N, 6.80\%; found: C 54.10, H 3.23, N 6.61\%. IR (KBr, $\left.\mathrm{cm}^{-1}\right)$ : $1726 \mathrm{~s}, 1601$ m, 1530 w, 1477 w, 1449 w, 1434 w, 1384 s, 1356 s, 1309 s, 1272 s, 1200 w, 1107 s, 1088 s, 1045 m, 1029 w, 951 w, 923 m, 839 w, 817 w, 780 m, 740 s, 693 m, 659 w, 596 w, 575 w, 497 w.

\section{Thermogravimetric analysis}

Thermogravimetric analysis was performed on a Mettler Toledo TGA/SDTA 851e in an aluminium crucible with a heating rate of 2 and/or $5{ }^{\circ} \mathrm{C} \mathrm{min}^{-1}$.

\section{X-ray crystal structure analyses of $\mathrm{L}, 1,2,3,4$ and 5}

Single crystals of $\mathbf{L}$, and complexes 1-5 were chosen under a microscope, placed in inert oil, and measured at $150 \mathrm{~K}$. The structures were solved by direct methods (SHELXL-2014) except for $\mathbf{L}$, which was solved with SHELX-97, and refined by full matrix least-squares procedures on $F^{2}$ using SHELXL2014. ${ }^{17}$ Hydrogen atom positions were calculated.

Crystal data for L. $M=448.46 \mathrm{~g} \mathrm{~mol}^{-1}, \mathrm{C}_{28} \mathrm{H}_{20} \mathrm{~N}_{2} \mathrm{O}_{4}$, triclinic, space group $P \overline{1}, a=4.8200(5) \AA, b=9.353(1) \AA, c=$ 11.782(1) $\mathrm{A}, \alpha=99.589(8)^{\circ}, \beta=99.411(8)^{\circ}, \gamma=90.265(8)^{\circ} ; V=$ 516.40(9) $\AA^{3}, Z=1, \rho=1.442 \mathrm{~g} \mathrm{~cm}^{-3}, \mu=0.098 \mathrm{~mm}^{-1}, F(000)$ $=234$, crystal size $=0.38 \times 0.28 \times 0.17 \mathrm{~mm}^{3}$. A total of 3568 
reflections $(2.21<\theta<27.04)$ were collected, of which 1735 reflections were unique $(R$ (int $)=0.0000)$. The structure was solved and refined using SHELXL-2014 to $R=0.0466$ for 1101 reflections with $I>2 \sigma(I), R=0.0895$ for all reflections, GOF = 0.986; $\mathrm{max} / \mathrm{min}$ residual electron density, 0.209 and $-0.193 \mathrm{e}$ $\AA^{-3}$.

Crystal data for 1. $M=705.41 \mathrm{~g} \mathrm{~mol}^{-1}, \mathrm{C}_{29} \mathrm{H}_{20} \mathrm{AgF}_{3} \mathrm{~N}_{2} \mathrm{O}_{7} \mathrm{~S}$, triclinic, space group $P \overline{1}, a=8.2703(17) \AA, b=12.916(3) \AA, c=$ 13.267(3) ̊̊, $\alpha=98.584(16)^{\circ}, \beta=99.288(16)^{\circ}, \gamma=98.638(17)^{\circ} ; V$ $=1360.69 \AA^{3}, Z=2, \rho=1.722 \mathrm{~g} \mathrm{~cm}^{-3}, \mu=0.891 \mathrm{~mm}^{-1}, F(000)$ $=708$, crystal size $=0.02 \times 0.11 \times 0.23 \mathrm{~mm}^{3}$. A total of 11364 reflections were collected $(1.58<\theta<25.37)$, of which 4893 reflections were unique $(R($ int $)=0.1894)$. The structure was solved and refined using SHELXL-2014 to $R=0.0922$ for 2560 reflections with $I>2 \sigma(I), R=0.1699$ for all reflections, GOF = 1.094; $\mathrm{max} / \mathrm{min}$ residual electron density, 0.671 and $-0.715 \mathrm{e}$ $\AA^{-3}$.

Crystal data for 2. $M=1474.88 \mathrm{~g} \mathrm{~mol}^{-1}$, $\mathrm{Ag}_{2} \mathrm{C}_{60} \mathrm{H}_{48} \mathrm{~F}_{6} \mathrm{~N}_{4} \mathrm{O}_{16} \mathrm{~S}_{2}$, triclinic, space group $P \overline{1}, a=8.2252(16)$ $\AA, b=14.362(3) \AA, c=24.711(5) \AA, \alpha=96.20(3)^{\circ}, \beta=96.65(3)^{\circ}$, $\gamma=104.58(3)^{\circ} ; V=2777(1) \AA^{3}, Z=2, \rho=1.764 \mathrm{~g} \mathrm{~cm}^{-3}, \mu=$ $0.879 \mathrm{~mm}^{-1}, F(000)=1488$, crystal size $=0.46 \times 0.33 \times 0.18$ $\mathrm{mm}^{3}$. A total of 44456 reflections $(1.48<\theta<24.10)$ were collected, of which 8275 reflections were unique $(R(\mathrm{int})=0$. 0719). The structure was solved and refined using SHELXL2014 to $R=0.0770$ for 7530 reflections with $I>2 \sigma(I), R=$ 0.0814 for all reflections, GOF $=1.018 ; \mathrm{max} / \mathrm{min}$ residual

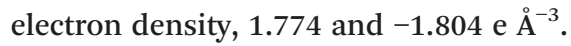

Crystal data for 3. $M=664.41 \mathrm{~g} \mathrm{~mol}^{-1}, \mathrm{C}_{30} \mathrm{H}_{26} \mathrm{AgN}_{3} \mathrm{O}_{8}$, triclinic, space group $P \overline{1}, a=8.331(3) \AA, b=12.208(4) \AA, c=$ 14.076(3) $\AA$, $\alpha=97.35(2)^{\circ}, \beta=105.78(3)^{\circ}, \gamma=97.30(3)^{\circ} ; V=$ $1346.53 \AA^{3}, Z=2, \rho=1.64 \mathrm{~g} \mathrm{~cm}^{-3}, \mu=0.808 \mathrm{~mm}^{-1}, F(000)=$ 676 , crystal size $=0.03 \times 0.11 \times 0.15 \mathrm{~mm}^{3}$. A total of 11364 reflections were collected $(1.58<\theta<25.37)$, of which 4784 reflections were unique $(R($ int $)=0.131)$. The structure was solved and refined using SHELXL-2014 to $R=0.050$ for 1993 reflections with $I>2 \sigma(I), R=0.143$ for all reflections, GOF = 0.868; $\mathrm{max} / \mathrm{min}$ residual electron density, 0.609 and $-0.334 \mathrm{e}$ $\AA^{-3}$.

Crystal data for 4. $M=650.38 \mathrm{~g} \mathrm{~mol}^{-1}, \mathrm{AgC}_{29} \mathrm{H}_{24} \mathrm{~N}_{3} \mathrm{O}_{8}$, triclinic, space group $P \overline{1}, a=8.2044(4) \AA, b=9.4246(4) \AA, c=$ 16.7815(8) $\AA, \alpha=93.942(4)^{\circ}, \beta=96.876(4)^{\circ}, \gamma=91.701(4)^{\circ} ; V=$ 1284.2(1) $\AA^{3}, Z=2, \rho=1.682 \mathrm{~g} \mathrm{~cm}^{-3}, \mu=0.845 \mathrm{~mm}^{-1}, F(000)$ $=660$, crystal size $=0.26 \times 0.13 \times 0.10 \mathrm{~mm}^{3}$. A total of 23307 reflections $(1.22<\theta<25.07)$ were collected, of which 4296 reflections were unique $(R($ int $)=0.1375)$. The structure was solved and refined using SHELXL-2014 to $R=0.0608$ for 3622 reflections with $I>2 \sigma(I), R=0.0734$ for all reflections, GOF = 1.084; $\mathrm{max} / \mathrm{min}$ residual electron density 1.541 and $-0.767 \mathrm{e}^{-3}$.

Crystal data for 5. $M=618.34 \mathrm{~g} \mathrm{~mol}^{-1}, \mathrm{C}_{28} \mathrm{H}_{20} \mathrm{AgN}_{3} \mathrm{O}_{7}$, monoclinic, space group $C 2 / c, a=32.985(2) \AA, b=5.4535(2)$ $\AA, c=14.4690(9) \AA, \beta=112.955(5)^{\circ} ; V=2396.6(2) \AA^{3}, Z=4, \rho=$ $1.714 \mathrm{~g} \mathrm{~cm}^{-3}, \mu=0.898 \mathrm{~mm}^{-1}, F(000)=1248$, crystal size $=$ $0.30 \times 0.25 \times 0.08 \mathrm{~mm}^{3}$. A total of 32569 reflections $(2.7<\theta$ $<29.3)$ were collected, of which 2714 reflections were unique $(R($ int $)=0.070)$. The structure was solved and refined using
SHELXL-2014 to $R=0.0529$ for 3213 reflections with $I>2 \sigma(I)$, $R=0.062$ for all reflections, $\mathrm{GOF}=1.084 ; \mathrm{max} / \mathrm{min}$ residual electron density, 3.2597 and -0.603 e $\AA^{-3}$.

All the crystal structures have been deposited at the CCDC 1413537-1413540 (L, 3, 2, 5), 1547594 (1), 1547595 (4).

\section{Results and discussion}

\section{Experimental strategy}

Based on the solubility of the reactants, a diffusion method was employed to obtain single crystals of the solvent-free silver coordination polymers and to co-crystallize methanol or ethanol molecules in order to obtain suitable new single crystals allowing the comparison of the effect of the presence and size of a solvent molecule. Methanol was chosen as it is a suitable solvent for silver salts and ligands; ethanol was also tested in order to study the influence of a slightly bigger solvent molecule with similar properties to methanol. Furthermore, considering the crucial influence of anions on the structure in the solid state, we focused our study on triflate and nitrate ions. The two-dimensional nitrate and its counterpart, the three-dimensional triflate, are similar in their possible coordination with silver ions via three different O-atoms. It is also known that the O-atoms of these counter ions may undergo H-bonding with solvent molecules. $^{9}$

\section{Characterization}

Single crystals of $\mathbf{L}$ suitable for X-ray single crystal diffraction measurement were obtained by recrystallizing the powder of $\mathbf{L}$ from DMF solution. $\mathbf{L}$ crystallizes in the triclinic space group $P \overline{1}$ with one half molecule per asymmetric unit. As shown in Fig. 1b, the ligand adopts an anti configuration with the two pyridine planes parallel to each other; an inversion center is located at the centroid of the anthracene ring. The angle between the pyridine plane and the anthracene plane is $76.77^{\circ}$, while the ester group of nicotinic acid and the corresponding pyridine ring are almost coplanar with $c a$. $2^{\circ}$. The distance from $\mathrm{C} 2$ to $\mathrm{C}^{\prime}$ is $15.221(4) \AA$. The weak $\mathrm{H}$-bonding interactions between $\mathrm{O} 1$ of the ester group and the $\mathrm{C} 12$ '- $\mathrm{H}_{12}$ ' group of the anthracene moiety, as well as that between $\mathrm{O} 2$ and $\mathrm{H}^{\prime}-\mathrm{C} 4^{\prime}$ of the pyridine ring of next neighbor molecules result in the formation of a $2 \mathrm{D}$ sheet structure (Fig. 1b). The distance between the nearest anthracene ring planes is $3.422 \AA$ with an offset of $3.39 \AA$ and a centroid-centroid distance between the central rings of $4.82 \AA$.

L shows an absorption maximum at $344 \mathrm{~nm}$ (Fig. 10), and its emission spectrum upon excitation at this wavelength is found to have a broad maximum at around $457 \mathrm{~nm}$ which could correspond to excimer formation, ${ }^{7}$ while the intramolecular transitions of the anthracene moieties are found at around $420 \mathrm{~nm}$. In comparison, the offset in pure anthracene is $5.44 \AA$, with a centroid-centroid separation between the central rings of $6.04 \AA{ }^{10}$ resulting in a fluorescence spectrum without an excimer band. ${ }^{11}$ 
The solvent free compound 1, $\left[\mathrm{AgL}\left(\mathrm{CF}_{3} \mathrm{SO}_{3}\right)\right]_{n}$, has been obtained from methanol and DCM. It crystallizes in the triclinic space group $P \overline{1}$ with one ligand $\mathbf{L}$, one silver ion and one triflate ion in its asymmetric unit. The ligand $\mathbf{L}$ adopts the anti configuration as in the free ligand. The angle between the two pyridine rings in one ligand $\mathbf{L}$ molecule is $4.81^{\circ}$, while the angle between the pyridine ring planes and the anthracene mean planes is $58.6^{\circ}$ on average. As illustrated in Fig. 2, the coordination of the pyridine rings to the silver ions leads to a one-dimensional zigzag chain. In fact, the silver ions are coordinated by two $\mathrm{N}$-atoms of two ligand molecules at an angle of (N1-Ag-N2') 172.9(4) ${ }^{\circ}$, with an $\mathrm{Ag}$ $\mathrm{N} 1$ of 2.177(9) $\AA$ and an Ag-N2' of 2.174(9) $\AA$, yielding a 1D chain. In addition, two oxygen atoms from two triflate anions are linked by weaker bonds to each silver ion (Ag1-O6, 2.692(9) and Ag1-O6', 2.666(9) ^), acting as bridging donors to a silver ion in a parallel coordination polymer, resulting in a double-chain motif. The silver ion coordination sphere is completed by a weakly coordinating oxygen atom from one of the two triflate anions (Ag1-O7, 3.138(9) Å). The coordination geometry around the $\mathrm{Ag}$ ion can thus be described as a distorted trigonal bipyramid $\left(\tau_{5}=0.57\right)$. The structural motif can be described as $\cdots \mathrm{ABA}^{\prime} \mathrm{B}^{\prime} \cdots$ double chains with a $\mathrm{Ag}-\mathrm{Ag}$ distance of 3.741(2) A between A and B. In contrast, between $\mathrm{A}^{\prime}$ and $\mathrm{B}$ chains there is no direct interaction with the shortest $\mathrm{Ag}-\mathrm{Ag}$ of 4.933(2) A. Between A and B chains, the distances between neighboring anthracene rings (3.523 $\AA$ ), the centroid-centroid separations (4.491 $\AA$ ) and the offset (ca. $2.77 \AA$ ) are longer, respectively similar, than those in $\mathrm{A}^{\prime} \mathrm{B}$ adjacent chains with $3.481,4.446$ and $2.78 \AA$, respectively. Adjacent stacks of chains present short contacts between the pyridine rings (C4-C4", $3.298 \AA$ A) and H-bonding involving O-atoms of the carboxyl moiety and the pyridine rings $\left(\mathrm{O} 4{ }^{\prime} \mathrm{H}^{\prime} 4^{\prime}-\mathrm{C} 4{ }^{\prime}, 3.36(2) \AA\right.$ and $\left.\mathrm{C} 25-\mathrm{H} 25 \cdots \mathrm{O} 1^{\prime}, 3.28(2) \AA\right)$.

Complex 2, $\left\{\left[\mathrm{AgL}\left(\mathrm{SO}_{3} \mathrm{CF}_{3}\right) \mathrm{MeOH}\right]_{2}\right\}_{n}$, crystallizes in the triclinic space group $P \overline{1}$ (Fig. 3). The asymmetric unit contains two crystallographically independent silver ions, two ligand molecules in the anti conformation, two triflate anions and two methanol molecules. Within one ligand, the angles between the pyridine rings are $3.94^{\circ}$ on average, while the average angle between the pyridine ring planes and the anthracene mean planes is about $59.4^{\circ}$. The first ligand comprising

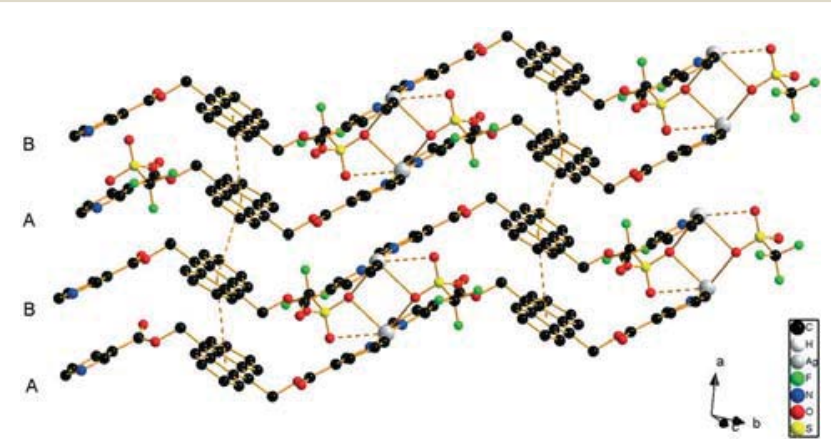

Fig. 2 Packing in the crystal structure of 1 (H-atoms are omitted for clarity; orange dotted lines indicate short contacts).

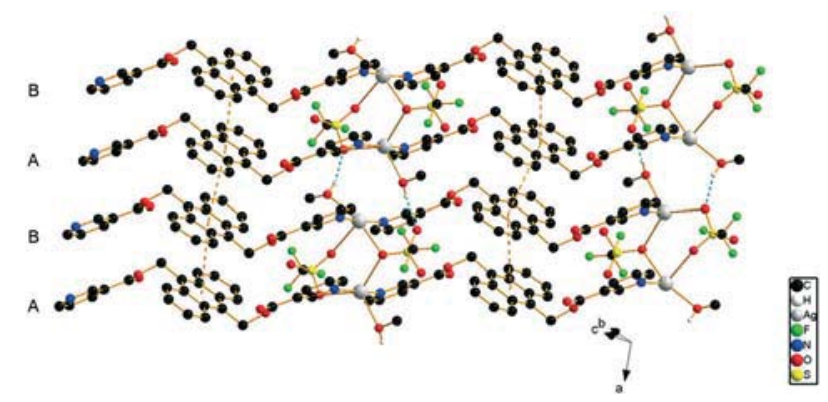

Fig. 3 Packing in the crystal structure of 2 ( $\mathrm{H}$-atoms are omitted for clarity; blue dotted lines indicate $\mathrm{H}$-bonding).

$\mathrm{N} 1$ and $\mathrm{N} 2$ has a N-N distance of $c a$. 14.73(1) $\AA$, while the second ligand measures 14.90(1) $\AA$ along N3 and N4. As shown in Fig. 3, Ag1 is five-coordinated by two nitrogen atoms from two ligand molecules with Ag1-N1 $=2.244(7)$ and Ag1-N4' = 2.262(7) $\AA$ with an N1-Ag1-N4' angle of almost $170^{\circ}$, two oxygen atoms from two triflate anions with Ag1-O9 $=2.697(7)$ and $\mathrm{Ag} 1-\mathrm{O} 14^{\prime}=2.749(5) \AA$, and one oxygen atom from methanol with $\mathrm{Ag} 1-\mathrm{O} 12=2.677(9) \AA$. Ag1 has thus an approximate coordination geometry of a trigonal bipyramid with an angle sum of $c a .357^{\circ}$ with the O-donors $\left(\tau_{5}=0.61\right)$.

The Ag2 ion is also five-coordinated, with N2 and N3 affording a shorter coordination than the equivalent binding for Ag1, namely with 2.193(7) ^ for both and with an N2$\mathrm{Ag} 2-\mathrm{N} 3$ angle of nearly $170^{\circ}$. The $\mathrm{O}^{\prime}$-atom of one triflate anion acts as the bridging donor atom between $\mathrm{Ag} 2$ and $\mathrm{Ag} 1^{\prime}$ of a neighboring chain with an Ag2-O9' distance of 2.868(8) A. $\mathrm{Ag} 2$ is also connected to $\mathrm{O} 13$ of a second anion with 2.676(7) $\AA$. The methanol molecule completes the coordination sphere of Ag2 by binding with its O16-atom at ca. 2.63(1) A. In contrast to Ag1, the coordination sphere geometry of Ag2 is far from being trigonal bipyramidal and can rather be described as distorted octahedral with one missing corner or as square pyramidal $\left(\tau_{5}(\mathrm{Ag} 2)=0.08\right)$. The bridging between two neighboring chains occurs for one of the anions via 09 and for the other via $\mathrm{O} 13$ and $\mathrm{O} 14$ with an average $\mathrm{Ag}-\mathrm{O}$ distance of 2.72 $\AA$. It results in the double-chain structure $\cdots \mathrm{ABA}^{\prime} \mathrm{B}^{\prime} \cdots$ in which Ag1 is bridged by two anions to Ag2' and vice versa. The weaker bonding of the ligands to silver in 2 compared to 1 leads to a long intra-chain Ag-Ag distance in 2 of 17.347(7) $\AA$, while the closest Ag-Ag distance (4.006(1) $\AA$ ) is found between double chains and is much longer than the $\mathrm{Ag}-\mathrm{Ag}$ van der Waals contact distance of $3.44 \AA{ }^{12}$ excluding the $\mathrm{Ag}-\mathrm{Ag}$ bonds, unlike in some of the Ag-containing double-chains that have been reported in the literature. ${ }^{10,12} \mathrm{H}$-bonding in compound 2 leads to the linking of the chains into a 3D network. Fig. 3 indicates a similar $\cdots \mathrm{ABA}^{\prime} \mathrm{B}^{\prime} \cdots$ packing mode with the anions bridging the $\mathrm{AB}$ chains as in 1 , while between $\mathrm{B}$ and $\mathrm{A}^{\prime}$, and between $\mathrm{B}^{\prime}$ and $\mathrm{A}$, the methanol molecules are found. The solvent molecules additionally form $\mathrm{H}$-bonds with the next double-chain, acting as $\mathrm{H}$-atom donors between 016 and 014 (2.69(2) ̊).

The neighboring anthracene planes from chains A and $\mathrm{B}$ are parallel, with an average distance of $3.601 \AA$ between the 
planes, and an average centroid-centroid distance of $c a .4 .16$ $\AA$ (offset of $2.11 \AA$ ). Between chains B and $\mathrm{A}^{\prime}$, the anthracene planes are spaced by $c a$. $3.50 \AA$, offset by $c a .2 .22 \AA$ and have a centroid-centroid separation of $4.15 \AA$ (Table 1 ).

Compound 3, $\left[\mathrm{AgL}\left(\mathrm{NO}_{3}\right) \mathrm{MeOH}\right]_{n}$, crystallizes in the triclinic space group $P \overline{1}$. The asymmetric unit contains one silver ion, one ligand molecule $\mathbf{L}$, one nitrate anion and one methanol molecule, and there are two of such entities in each unit cell. Similar to those in 1 and 2 , the $\mathrm{Ag}(\mathrm{I})$ ions are connected to two N-atoms from two different ligands to form a 1D Ag-L-Ag-L chain. The Ag-N distances are 2.171(5) (Ag1-N1) and 2.179(4) (Ag1-N2') $\AA$, and the N1-Ag-N2' angle is close to linear, $c a \cdot 176.9^{\circ}$, which is larger than that in 1 and 2 . The ligand $\mathbf{L}$ adopts the anti configuration as in the free ligand. The two pyridine rings of the ligand are almost parallel with an angle of $c a .5^{\circ}$, while the angle between the anthracene entity and the pyridine rings is $c a .64 .5^{\circ}$ on average. Within a chain, the $\mathrm{Ag}-\mathrm{Ag}$ distance is 16.781(9) $\AA$ long. Two parallel chains are bridged at the $\mathrm{Ag}(\mathrm{I})$-ions by two nitrate anions with $\mathrm{Ag}-\mathrm{O}$ distances of 2.695(4) (Ag1-O7) and 2.882(5) $\AA$ ( $\left.\mathrm{Ag} 11^{\prime}-\mathrm{O} 7\right)$, giving the metal ion a seesaw type of coordination geometry $\left(\tau_{4}=0.62\right)$, similar to the one found in $\left\{\left[\operatorname{Ag}\left(\mathbf{L}^{\prime}\right)\right]\left(\mathrm{NO}_{3}\right)\left(\mathrm{H}_{2} \mathrm{O}\right)_{2}\right\}_{n}$, where $\mathbf{L}^{\prime}$ is a similar ligand but without the anthracene entity. ${ }^{13}$ The $\mathrm{Ag}-\mathrm{Ag}$ distance in 3 between the two chains A and B is 4.682(6) A, and the two adjacent anthracene rings are completely parallel (distance of $3.45 \AA$ ) with an offset between the anthracene planes of $c a$. $1.94 \AA$ and a centroid-centroid separation of $c a$. $3.97 \AA$. For adjacent chains $\mathrm{B}$ and $\mathrm{A}^{\prime}$ (Fig. 4), the shortest distance between neighboring $\mathrm{Ag}(\mathrm{I})$ ions is 3.679(6) $\AA$. A methanol molecule is intercalated between these two chains with a distance of $>3.0 \AA$ between its oxygen atom 08 and the $\mathrm{Ag}(\mathrm{I})$ ions, so the methanol with a 0.04 contribution in the $\mathrm{BV}$ could be considered to be weakly bonded to $\mathrm{Ag}$. The anthracene planes from chains $\mathrm{B}$ and $\mathrm{A}^{\prime}$ are also parallel with a distance of $c a .3 .53 \AA$, and a centroid-centroid separation between the central rings of anthracene of $4.54 \AA$, offset by $2.85 \AA$. Hence, the interactions between anthracene moieties from adjacent $\mathrm{A}$ and $\mathrm{B}$ chains are stronger than those between $\mathrm{B}$ and $\mathrm{A}^{\prime}$ chains. Close contacts are found between the ester oxygen atom $\mathrm{O} 3$ and the $\mathrm{C} 5$ atom of an adjacent ligand with a distance of 3.459(6)A. O4 is involved in H-bonding with a neigh-

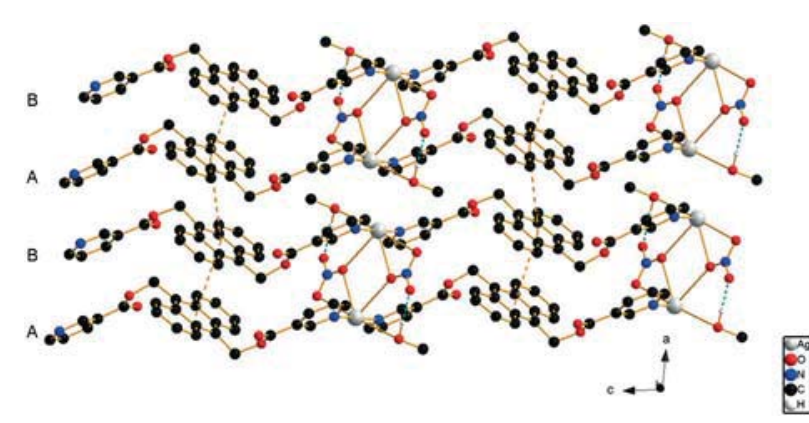

Fig. 4 Packing in the crystal structure of 3 (H-atoms are omitted for clarity; blue dotted lines indicate $\mathrm{H}$-bonding). boring ligand with distances of 3.277(7) and 3.239(6) ^ for C18-H18 $\cdots \mathrm{O} 4$ and $\mathrm{C} 19-\mathrm{H} 19 \cdots \mathrm{O} 4$, respectively. $\mathrm{O} 1$ is involved in H-bonding with a $\mathrm{CH}$ group of a neighboring anthracene ring with distances of 3.386(6) $\AA$ (C11-H11 $\cdots \mathrm{O} 1)$ and 3.561(7)

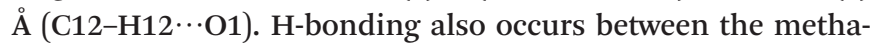
nol O-atom and a $\mathrm{C}-\mathrm{H}$ group of the pyridine ring with a distance of 3.297(7) ̊ for $\mathrm{C} 27-\mathrm{H} 27 \cdots \mathrm{O} 8$.

Compound 4, $\left\{\left[\mathrm{AgL}\left(\mathrm{NO}_{3}\right)\right] \mathrm{EtOH}\right\}_{n}$, crystallizes in the triclinic space group $P \overline{1}$. The asymmetric unit includes one ligand $\mathbf{L}$, one silver ion, one nitrate ion and one ethanol molecule. The two pyridine rings of the ligand $\mathbf{L}$ adopt the anti configuration and are almost parallel with an angle of $1.73^{\circ}$, whereas the pyridine ring planes and anthracene entities form an angle of $60.9^{\circ}$ on average. In the one-dimensional $\mathrm{Ag}-\mathrm{L}-\mathrm{Ag}-\mathbf{L}$ chain, the distance of $\mathrm{Ag}-\mathrm{N}$ is $c a .2 .16 \AA$, the N1$\mathrm{Ag}-\mathrm{N} 2^{\prime}$ angle is $172.4(2)^{\circ}$ and the $\mathrm{Ag}-\mathrm{Ag}$ distance is 16.822(7) A. As displayed in Fig. 5, the silver ion is coordinated by N1 and $\mathrm{N}^{\prime}$ atoms of two neighboring ligands $\mathrm{L}$, $\mathrm{O}^{\prime}$ and $\mathrm{O6}^{\prime}$ atoms of the one nitrate anion $\left(\mathrm{Ag}^{-} \mathrm{O5}^{\prime}, 2.811(8)\right.$ and $\mathrm{Ag}-\mathrm{O6}^{\prime}$, $2.868(9) \AA)$ and the $\mathrm{O} 5$ atom of the second nitrate anion ( $\mathrm{Ag}$ O5, 2.882(7) Å). These result in a five-coordinated silver ion which has a distorted trigonal bipyramid geometry $\left(\tau_{5}=0.8\right)$.

The anthracene planes are parallel and the silver ions are connected by two bridging nitrate anions resulting in a $2 \mathrm{D}$ double chain motif. Furthermore, the chains via a series of inter-stack H-bonding interactions form a 3D pattern (C25'-

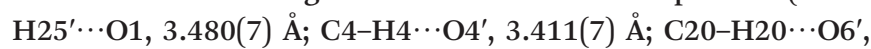

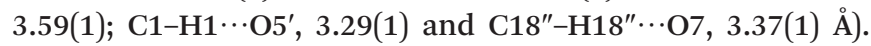
The $\mathrm{Ag}-\mathrm{Ag}$ distance between $\mathrm{AB}$ double chains (4.221(2) $\AA$ ) is longer than that in adjacent $\mathrm{A}^{\prime} \mathrm{B}$ chains $(4.177(2) \AA)$. The solvent molecules with a 0.02 contribution in the $\mathrm{BV}$ are intercalated between pairs of double chains leading to weak interactions with silver ions (Ag-O8, 3.25(1) ̊). Accordingly, in the $\mathrm{AB}$ double chains, the distance between anthracene planes (ca. $3.43 \AA$ ), the centroid-centroid separation (ca. $4.12 \AA$ ) and the offset of the anthracene planes (ca. 2.27 $\AA$ ) are shorter than those in adjacent A'B chains, 3.59, 4.329 and $2.42 \AA$, respectively.

The solvent-free compound $5,\left[\mathrm{AgL}\left(\mathrm{NO}_{3}\right)\right]_{n}$, has been obtained from ethanol and DMF. It crystallizes in the space group $C 2 / c$ with half of a molecule of ligand $\mathbf{L}$, half of a silver ion and half of a nitrate ion in the asymmetric unit. The

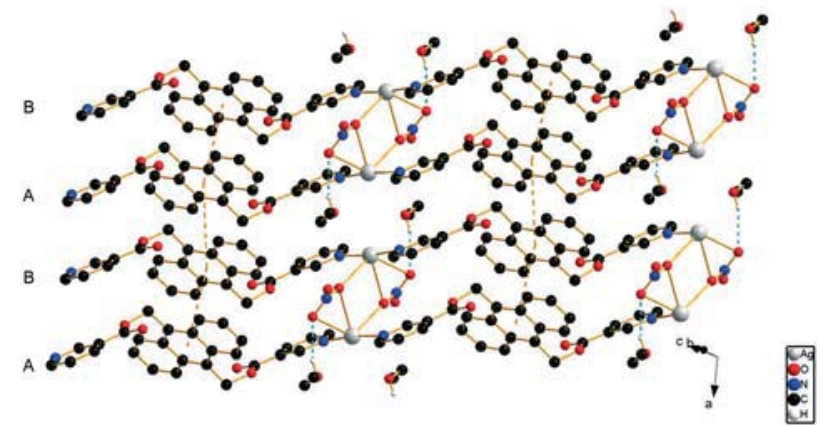

Fig. 5 Packing in the crystal structure of 4 (blue dotted lines indicate H-bonding). 
overall structure is also based on a 1D chain structure made of silver ions and ligand molecules (Fig. 6), but in contrast to compounds 1-4, no double-chains are formed; an inversion center is located at the centroid of anthracene. The silver ion is also found on an inversion center and linearly coordinated by two N-atoms from two different ligands with an $\mathrm{Ag}-\mathrm{N}$ distance of 2.196(5) $\AA$. The silver ion is also coordinated by two O-atoms from nitrate ions through weak bonds of $c a .2 .75 \AA$ on average, yielding a square planar geometry $\left(\tau_{4}=0\right)$.

The nitrate ions seem to connect the chains into a $3 \mathrm{D}$ framework, but they are lying on special positions (2-fold axis) with heavily disordered O-atoms. Thermogravimetry excludes the presence of a solvent molecule. Within one ligand, the planes containing the pyridine rings are parallel, while the angle between the pyridine ring and the anthracene moiety is $64.74^{\circ}$, within the range of compound 1 . Within the same chain, the $\mathrm{Ag}-\mathrm{Ag}$ distance is 19.029(1) A. Between chains, the shortest $\mathrm{Ag}-\mathrm{Ag}$ distance is 5.4535(2) $\AA$. This is due to the strong offset with the silver ion having short contacts with $\mathrm{C} 3$ and $\mathrm{C} 4$ of a parallel chain (3.033(7) and 3.315(6) ̊). H-bonding exists between $\mathrm{O} 1$ of one ligand and C3 of one neighbor and C7 of a parallel chain ligand (3.075(8) and 3.426(7) ^, respectively). Weak interactions between adjacent anthracene moieties can be observed at a distance of $3.449 \AA$ between the planes, with a centroid-centroid distance of $5.453 \AA$ and a very large offset of $c a .4 .22 \AA$ (see Fig. S6 and $\mathrm{S} 7 \dagger)$.

\section{Influence of anions and solvent on the packing pattern}

Nitrate and triflate can coordinate to silver ions via three different O-atoms and thus can influence the $\pi-\pi$ stacking arrangement of anthracene. ${ }^{14}$ In non-solvated compounds 1 and 5 , the bulky triflate ion in 1 leads to the packing of chains along the direction of the $a$-axis to form a slipped column with pairwise anthracene stacking (Fig. 7a). Consequently, each triflate ion strongly immobilizes a pair of parallel chains, which results in the maximization of the face-toface $\pi-\pi$ interactions ${ }^{15}$ between the anthracene planes ( $\mathrm{Ag}-\mathrm{O}$, ca. $2.67 \AA$ A). By contrast, the small nitrate ions in 5 make the connectivity between the chains along the direction of the

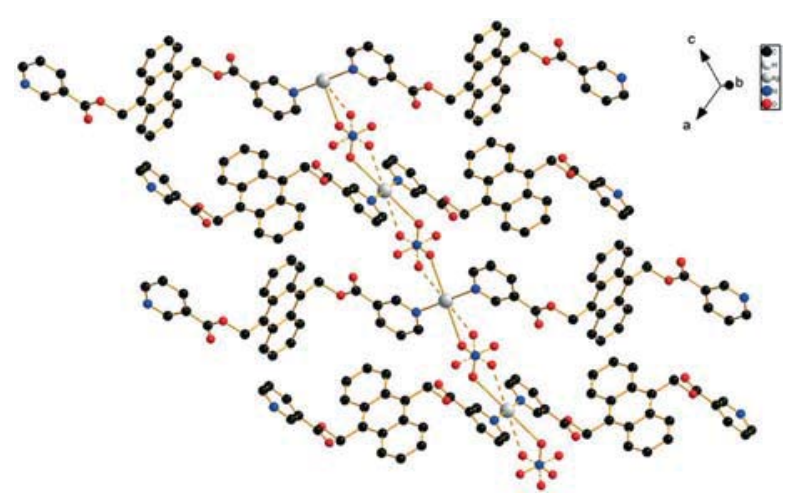

Fig. 6 Packing in the crystal structure of 5; $\mathrm{H}$ atoms are omitted for clarity. a)
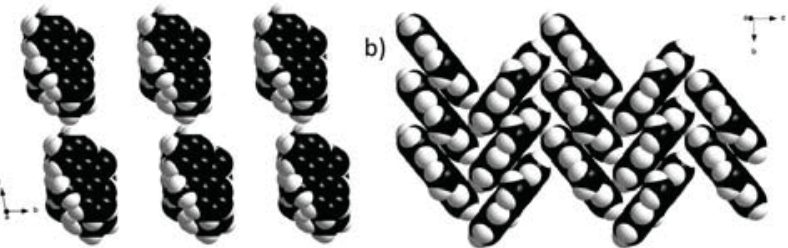

Fig. 7 a) Column stacking pattern of anthracene in compound 5 viewed along the crystallographic a-axis; b) herringbone molecular packing pattern of anthracene in compound 5 viewed along the crystallographic a-axis.

$c$-axis and the anthracene rings adopt a herringbone packing (Fig. 7b). In this case, the anthracene rings are weakly stacked in an anti-parallel arrangement with an interplanar angle of $78.46^{\circ}$ to promote edge-to-face $\mathrm{CH}-\pi$ interactions (Ag-O, ca. $2.75 \AA$ ). The packing pattern as well as the maximization of the $\pi$-orbital overlap can thus be affected by the size of the counter ion and its distance from the silver ions.

It is also known that nitrate and triflate anions, in the solid state, can coordinate via one, two or all three oxygen atoms to silver ions. The free oxygen atom(s) of such anions may undergo H-bonding with solvent molecules. ${ }^{10}$ Consequently, the solvent molecules influence the packing patterns by the effect of their intermolecular interactions (ability to create H-bonds) and their steric effect (carbochain length and spatial structure). For instance, methanol and ethanol molecules can be involved in H-bonding with the nitrate ion in 3 and 4 , respectively, and reorganize the counter ions between double chains (Fig. 8). In comparison with the antiparallel packing of 5, the $\mathrm{H}$-bonding network in 3 and 4 leads to thermodynamically more stable packing patterns.

As depicted in Fig. 8a and c, ethanol molecules "spread out" and are associated with two adjacent silver ions, whereas methanol molecules are weakly connected with one silver
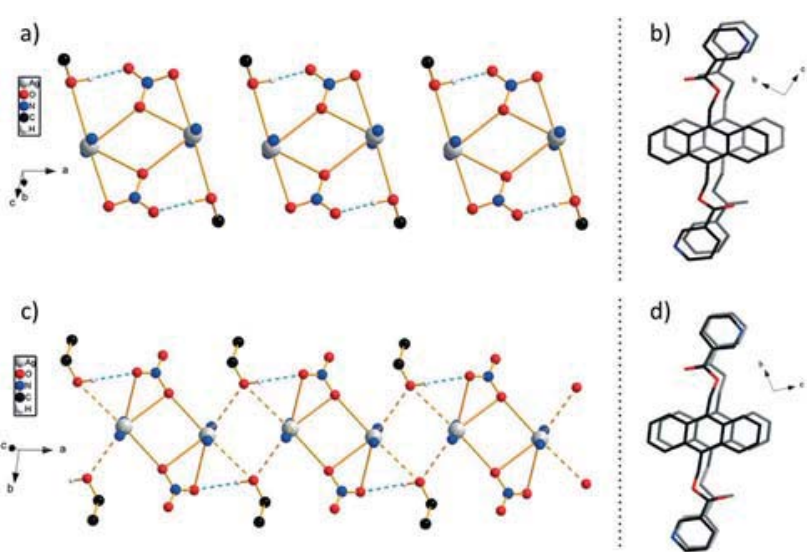

Fig. 8 (a) Solvent-assisted hydrogen-bonding network in the crystal structure of 3 (ligands are omitted for clarity; blue dotted lines indicate $\mathrm{H}$-bonding). (b) Packing pattern of 3, top view. (c) Solvent-assisted hydrogen-bonding network in the crystal structure of 4 (ligands are omitted for clarity; blue and yellow dotted lines indicate $\mathrm{H}$-bonding and short contacts, respectively). (d) Packing pattern of 4, top view. 

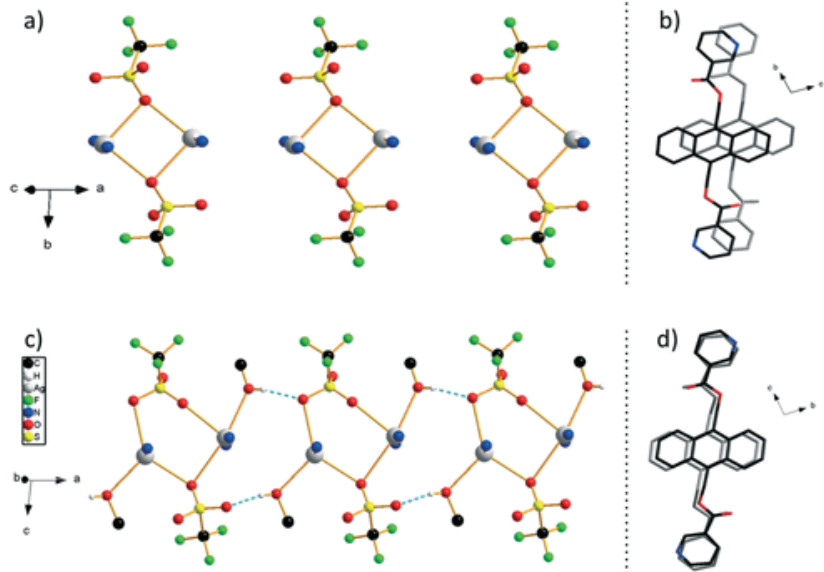

Fig. 9 (a) Crystal structure of 1 (ligands are omitted for clarity). (b) Packing pattern of 1, top view. (c) Solvent-assisted hydrogen-bonding network in the crystal structure of 2 (ligands are omitted for clarity; blue dotted lines indicate $\mathrm{H}$-bonding). (d) Packing pattern of 2, top view.

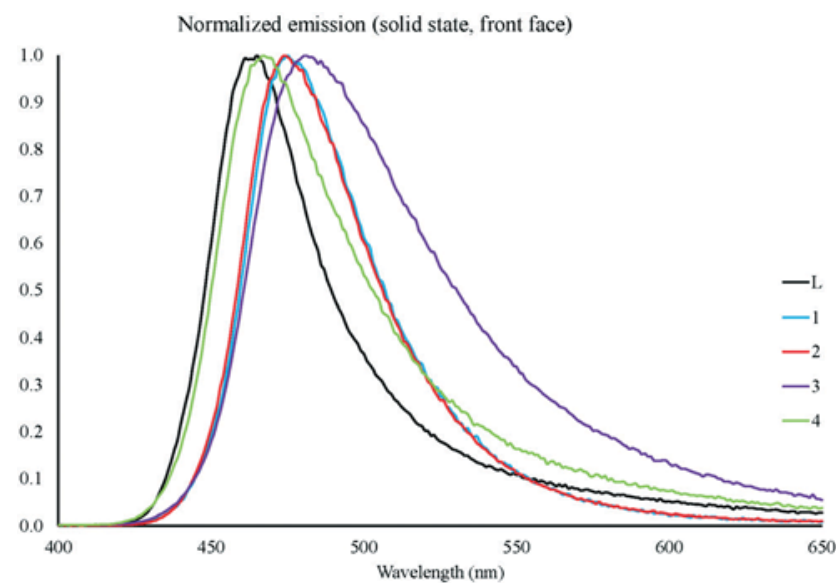

Fig. 10 Emission spectra for ligand $\mathrm{L}$ and complexes 1-4 upon excitation at a wavelength of $344 \mathrm{~nm}$.

ion. The difference of the carbon chain length between the two solvents leads thus to different shifts between parallel anthracene moieties. Consequently, the overlap ratio between the ligand molecules projected on each other changes from ca. $61 \%$ in 3 to $c a .77 \%$ in 4 (Fig. $8 \mathrm{~b}$ and d).
In triflate-based compounds $\mathbf{1}$ and 2, however, the $\mathrm{H}$-bonding network in 2 results in a smaller displacement along the $b$-axis with $c a$. $82 \%$ overlap instead of $c a .47 \%$ of overlap for 1 (Fig. 9). The H-bonding network in the triflate series thus maximizes the $\pi-\pi$ interactions between the anthracene moieties although the packing pattern remains slipped along the $a$-axis (Fig. 9c and d).

\section{Relationship between the packing pattern and photophysical properties}

The effect of the arrangement of the anthracene moieties on the solid-state luminescence properties was investigated by fluorescence spectra analysis of $L$ and compounds 1-4. Upon excitation at $344 \mathrm{~nm}$, steady-state emissions were collected at RT under ambient conditions using a front-face geometry on a Fluorolog-3 (Jobin Yvon) spectrophotometer equipped with an iHR-320 monochromator. As illustrated in Fig. 10, all compounds are highly emissive and possess similar emission profiles. The large Stokes shift of the broad emission with respect to the absorption is indicative of significant stabilization of the excited state with respect to the ground state species and is assigned to excimer formation. The solid-state emission spectra of compounds 1-4 are shifted bathochromically compared to the emission of $\mathrm{L}$ in the following order: $\mathrm{L}(465 \mathrm{~nm}) \approx 4(468$ $\mathrm{nm})<2(474 \mathrm{~nm}) \approx 1(475 \mathrm{~nm})<3(480 \mathrm{~nm})$.

The solid-state quantum yield was also investigated to analyze the emission efficiency of these compounds (Table 2). Among the double chain packing patterns, the electronwithdrawing triflate-based compounds 1 and 2 exhibit better quantum yields than $\mathrm{L}, 3$ and 4 . In comparison with 1 however, the solvent assisted H-bonding network in 2 leads to maximized $\pi-\pi$ interactions between the anthracene moieties that may be responsible for the further increase of the quantum yields. By the same token, in the nitrate-based compounds 3 and 4 with similar arrangements, the increase in the quantum yields is in agreement with the degree of $\pi-\pi$ interactions in the anthracene moieties.

In conclusion, one anthracene derivative ligand $\mathbf{L}$ and five Ag-L coordination polymers have been obtained. The X-ray single crystal diffraction experiments indicate that 1-5 are all 1D chain structures in which the ligand adopts an anti

Table 1 Summary of the rounded $\pi-\pi$ interactions between anthracene moieties in ligand L and complexes 1 to 5 ; planes and centroids were calculated with the anthracene cycle

\begin{tabular}{|c|c|c|c|c|c|}
\hline Compound & $\begin{array}{l}\text { Plane } i \text { with } \\
\text { plane } j\end{array}$ & $\begin{array}{l}\text { Symmetry } \\
\text { operation used }\end{array}$ & $\begin{array}{l}\text { Distance between adjacent } \\
\text { anthracene planes }(\AA)\end{array}$ & $\begin{array}{l}\text { Centroid-centroid distance between } \\
\text { adjacent anthracene planes ( } \mathrm{A})\end{array}$ & $\begin{array}{l}\text { Offset between anthracene } \\
\text { centroids }(\AA)\end{array}$ \\
\hline $\mathbf{L}$ & $\mathrm{AA}^{\prime}$ & $-1+x, y, z$ & 3.43 & 4.82 & 3.39 \\
\hline \multirow[t]{2}{*}{1} & $\mathrm{AB}$ & $-x,-y,-z$ & 3.52 & 4.49 & 2.78 \\
\hline & $\mathrm{BA}^{\prime}$ & $1-x,-y,-z$ & 3.48 & 4.45 & 2.77 \\
\hline \multirow[t]{2}{*}{2} & $\mathrm{AB}$ & $3-x, 2-y, 1-z$ & 3.59 & 4.16 & 2.11 \\
\hline & $\mathrm{BA}^{\prime}$ & $2-x, 2-y, 1-z$ & 3.50 & 4.15 & 2.22 \\
\hline \multirow[t]{2}{*}{3} & $\mathrm{AB}$ & $-x, 1-y, 1-z$ & 3.45 & 3.97 & 1.94 \\
\hline & $\mathrm{BA}^{\prime}$ & $1-x, 1-y, 1-z$ & 3.53 & 4.53 & 2.84 \\
\hline \multirow[t]{2}{*}{4} & $\mathrm{AB}$ & $2-x, 1-y, 1-z$ & 3.43 & 4.12 & 2.27 \\
\hline & $\mathrm{BA}^{\prime}$ & $1-x, 1-y, 1-z$ & 3.59 & 4.33 & 2.42 \\
\hline 5 & $\mathrm{AA}^{\prime}$ & $x,-1+y, z$ & 3.45 & 5.45 & 4.22 \\
\hline
\end{tabular}


Table 2 Summary of solid state fluorescence properties of ligand $L$ and complexes 1-4

\begin{tabular}{lllr}
\hline Compound & $\lambda_{\text {ex }}$ & $\lambda_{\text {em }}(\max )$ & $\Phi_{\mathrm{F}}[\%]$ \\
\hline Ligand & 344 & 465 & 7.1 \\
1 & 344 & 475 & 19.5 \\
2 & 344 & 474 & 22.4 \\
3 & 344 & 480 & 3.7 \\
4 & 344 & 468 & 4.8
\end{tabular}

conformation like that of the free ligand $\mathbf{L}$, but with slightly different lengths of $\mathbf{L}$ depending on the twist and packing. All of them show excimer emission in the solid state with a slight shift of the emission maxima depending also on the packing. The latter is tuned by the presence of different anions and the presence or absence of solvent molecules. It is interesting to note that the coordination effect and the presence of solvent molecules do not interfere much with the emission properties, making the ligands very versatile and predictable in most cases. It is also interesting to note that in comparison with the isonicotinic analogue, ${ }^{7}$ in which not only a slight blue shift was observed but also an absence of luminescence in the complex containing water, by changing the position of the $\mathrm{N}$-atom in the pyridinyl group and in turn the coordination and packing, a slight red shift could be obtained.

The authors thank the Fribourg Center of Nanomaterials FriMat, the Swiss National Science Foundation and the University of Fribourg for their generous support, the BioNanomaterials group at the Adolphe Merkle Institute for elemental analysis, and also Th. Bally, C. Bochet, B. Giese and C. Piguet for their fruitful discussions on excimer emissions.

\section{Notes and references}

1 H. B. Rosenstock, J. Chim. Phys. Phys.-Chim. Biol., 1968, 48, 532; A. Matsui, K. Mizuno and M. Kobayashi, J. Phys., Colloq., 1985, 7, 19; Z. Fei, N. Kocher, C. J. Mohrschladt, H. Ihmels and D. Stalke, Angew. Chem., Int. Ed., 2003, 42, 783.

2 R. C. Ropp and N. J. Warren, Luminescence and the Solid State, Elsevier, Amsterdam, 1991.

3 M. Montalti, L. Prodi and N. Zaccheroni, J. Fluoresc., 2000, 10, 71; S. Alves, F. Pina, M. T. Albelda, E. GarciaEspana, C. Soriano and S. V. Luis, Eur. J. Inorg. Chem., 2001, 405; P. D. Beer and P. A. Gale, Angew. Chem., 2001, 113, 502; Angew. Chem., Int. Ed., 2001, 40, 2556; T. Gunnlaugsson, A. P. Davis and M. Glynn, Chem. Commun., 2001, 2556.

4 M. D. Allendorf, C. A. Bauer, R. K. Bahkta and R. J. T. Houk, Chem. Soc. Rev., 2009, 1330.

5 B. D. Wagner, G. J. McManus, B. Moulton and M. J. Zaworotko, Chem. Commun., 2002, 2176.

6 D.-Z. Wang, C.-S. Liu, J.-R. Li, L. Li, Y.-F. Zeng and X.-H. Bu, CrystEngComm, 2007, 9, 289; T.-L. Hu, J.-R. Li, Y.-B. Xie and X.-H. Bu, Cryst. Growth Des., 2006, 6, 648.
7 J. Chen, A. Neels and K. M. Fromm, Chem. Commun., 2010, 46, 8282.

8 T. Vig Slenters, I. Hauser-Gerspach, A. U. Daniels and K. M. Fromm, J. Mater. Chem., 2008, 18, 5359; P. S. Brunetto and K. M. Fromm, Chimia, 2008, 62, 249; O. Gordon, T. Vig Slenters, P. S. Brunetto, A. E. Villaruz, D. E. Sturdevant, M. Otto, R. Landmann and K. M. Fromm, Antimicrob. Agents Chemother., 2010, 54, 4208; K. Belser, T. Vig Slenters, C. Pfumbidzai, G. Upert, L. Mirolo, K. M. Fromm and H. Wennemers, Angew. Chem., Int. Ed., 2009, 48, 3661; P. S. Brunetto, T. Vig Slenters and K. M. Fromm, Materials, 2011, 4, 355; I. Chevrier, J. Sagué, P. S. Brunetto, N. Khanna, Z. Rajacic and K. M. Fromm, Dalton Trans., 2013, 42, 217; J. Girard, P. S. Brunetto, O. Braissant, Z. Rajacic, N. Khanna, R. Landmann, A. U. Daniels and K. M. Fromm, C. R. Chim., 2013, 16, 550; M. Varisco, N. Khanna, P. S. Brunetto and K. M. Fromm, ChemMedChem, 2014, 9, 1221.

9 A. Y. Robin and K. M. Fromm, Coord. Chem. Rev., 2006, 250, 2127; K. M. Fromm, J. L. Sagué and A. Y. Robin, Inorg. Chim. Acta, 2013, 403, 2; T. Steiner, Angew. Chem., Int. Ed., 2002, 41, 48; S. Seth, V. Lee, J. Yana, S. Zain, A. Cunha, V. Ferreira, A. Jordão, M. de Souza, S. Wardell, J. Wardell and E. Tiekink, CrystEngComm, 2014, 17, 2255; L. Salonen, M. Ellermann and F. Diederich, Angew. Chem., Int. Ed., 2011, 50, 4808.

10 R. Mason, Acta Crystallogr., 1964, 17, 547.

11 H. Hu, R. A. Fuh, J. Li, A. Corkan and J. S. Lindsey, Photochem. Photobiol., 1998, 68, 141.

12 F. F. Li, J. F. Ma, Sh. Y. Song, J. Yang, P. Q. Jia and N. H. Hu, Cryst. Growth Des., 2006, 6, 209.

13 A. Y. Robin, M. Meuwly, K. M. Fromm, H. Goesmann and G. Bernardinelli, CrystEngComm, 2004, 6, 336.

14 P. Manna, S. K. Seth, M. Mitra, A. Das, N. J. Singh, S. R. Choudhury, T. Kar and S. Mukhopadhyay, CrystEngComm, 2013, 15, 7879; S. K. Seth, D. Sarkar and T. Kar, CrystEngComm, 2011, 13, 4528; S. K. Seth, I. Saha, C. Estarellas, A. Frontera, T. Kar and S. Mukhopadhyay, Cryst. Growth Des., 2011, 11, 3250; S. K. Seth, P. Manna, N. J. Singh, M. Mitra, A. D. Jana, A. Das, S. R. Choudhury, T. Kar, S. Mukhopadhyay and K. S. Kim, CrystEngComm, 2013, 15, 1285; C. Janiak, Dalton Trans., 2003, 2781.

15 P. Manna, S. Seth, M. Mitra, S. Choudhury, A. Bauzá, A. Frontera and S. Mukhopadhyay, Cryst. Growth Des., 2014, 14, 5812; P. Manna, S. Seth, A. Bauzá, M. Mitra, S. Choudhury, A. Frontera and S. Mukhopadhyay, Cryst. Growth Des., 2014, 14, 747; S. K. Seth, CrystEngComm, 2013, 15, 1772; P. Manna, S. Seth, A. Das, J. Hemming, R. Prendergast, M. Helliwell, S. Choudhury, A. Frontera and S. Mukhopadhyay, Inorg. Chem., 2012, 51, 3557.

16 M. W. Müller, R. W. Amidon and P. O. Tawney, J. Am. Chem. Soc., 1955, 117, 2845.

17 G. M. Sheldrick, Acta Crystallogr., Sect. A: Found. Crystallogr., 1990, 46, 467; G. M. Sheldrick, SHELX-97, University of Göttingen, Göttingen, Germany, 1997. 